\title{
Ragam Bahasa dan Sastra Dalam Geguritan Luh Lutung: Sebagai Media Pendidikan Bagi Masyarakat
}

\author{
Luh Putu Puspawati \\ Program Studi Sastra Bali, Fakultas Ilmu Budaya, Universitas Udayana. \\ puspawati1960@yahoo.co.id
}

Ida Bagus Made Wisnu Parta

Program Studi Pendidikan Bahasa Indonesia Dan Daerah, Fakultas Keguruan Dan Ilmu Pendidikan, Universitas Dwijendra.

wisnu.goes@gmail.com

\begin{abstract}
Abstrak
Ragam bahasa dan sastra yang terdapat pada karya sastra tradisional Bali dapat dipakai sebagai media pendidikan bagi masyarakat. Salah satunya terdapat dalam teks Geguritan Luh Lutung yang digunakan sebagai objek penelitian. Teks Geguritan Luh Lutung mengandung nilai-nilai filsafat kehidupan yang nantinya dapat dipakai sebagai media pendidikan dalam tradisi mabebasan. Tradisi mabebasan merupakan perihal berbahasa tentang pemberian arti dan pemberian makna dalam karya sastra tradisional. Permasalahan yang ada dalam penelitian ini adalah bagaimanakah ragam bahasa dan ragam sastra dalam teks Geguritan Luh Lutung sebagai media pendidikan bagi masyarakat?. Tujuan dari penelitian ini untuk melestarikan khazanah budaya khususnya dalam karya sastra tradisional Bali. Selain itu, untuk mengetahui ragam bahasa dan ragam sastra dalam teks Geguritan Luh Lutung sebagai media pendidikan bagi masyarakat. Penelitian ini bersifat kualitatif dengan menggunakan metode deskriptif analitik. Metode deskriptif analitik adalah suatu metode yang berfungsi untuk mendeskripsikan atau memberi gambaran terhadap objek yang diteliti melalui data atau sampel. Teori yang digunakan dalam penelitian ini adala teori stilistika. Istilah gaya bahasa dengan stile (sebagai pengindonesiaan dari style) pada hakikatnya merupakan teknik, teknik pemilihan ungkapan kebahasaan, dirasa dapat mewakili sesuatu yang akan diungkapkan. Hasil analisis dalam penelitian ini, berupa: (1) ragam bahasa dalam teks Geguritan Luh Lutung yang ditemukan berupa stratifikasi Bahasa Bali. Penggunaan Bahasa Bali Alus ditemukan pada ranah keluarga percakapan antartokoh Made Saliksik kepada orang tuanya dan ranah masyarakat dalam percakapan antartokoh Made Saliksik dan Luh Lutung terhadap gurunya. (2) Ragam sastra dalam teks Geguritan Luh Lutung yang digunakan dalam penelitian ini berupa gaya bahasa perbandingan, seperti: perumpamaan, personifikasi, antitesis. Gaya bahasa pertentangan, seperti: Hiperbola, dan litotes. Gaya bahasa pertautan, seperti: Eufemisme, dan antonomasia.
\end{abstract}

Kata Kunci: Ragam Bahasa, Sastra, Geguritan, dan Pendidikan

\begin{abstract}
Variety of language and literature found in traditional Balinese literature can be used as a medium of education for the community. One of them is in the text Geguritan Luh Lutung which is used as the object of research. The text Geguritan Luh Lutung contains the values of the philosophy of life which can later be used as a medium of education in the tradition mabebasan. The tradition mabebasan is a matter of language about giving meaning and giving meaning in traditional literature. The problem in this research is how the variety of language and variety of literature in the text Geguritan Luh Lutung as a medium of education for the community?. The purpose of this research is to preserve cultural treasures, especially in traditional Balinese literature. In addition, to find out the variety of language and variety of literature in the text Geguritan Luh Lutung as an educational medium for the community. This research is qualitative using descriptive analytic method. Analytical descriptive method is a
\end{abstract}


method that serves to describe or provide an overview of the object under study through data or samples. The theory used in this research is stylistic theory. The term style with stile (as indonesia of style) is essentially a technique, a technique of linguistic expression elections, deemed to represent something that is going to be revealed. The results of the analysis in this study are: (1) the variety of languages in the text Geguritan Luh Lutung found in the form of Balinese language stratification. The use of the Balinese Alus language is found in the family realm of conversation between Made Saliksik characters to his parents and the realm of society in conversations between Made Saliksik and Luh Lutung characters to their teachers. (2) The variety of literature in thetext Geguritan Luh Lutung used in this study is in the form of comparative language styles, such as: parable, personification, antithesis. Contradictory language styles, such as: hyperbole, and litotes. Linking language styles, such as: euphemisms, and antonyms.

\section{Keywords: Variety of Languages, Literature, Geguritan, and Education}

\section{PENDAHULUAN}

Ragam bahasa adalah variasi bahasa menurut pemakaian yang berbeda-beda menurut topik yang dibicarakan, menurut hubungan pembicara, kawan bicara, dan orang yang dibicarakan, serta menurut medium pembicaraan (Kridalaksana, 2001: 184). Ragam bahasa dapat dibagi menjadi tiga macam, yaitu: (1) ragam bahasa berdasarkan pokok pembicaraan (ragam bahasa undang-undang, ragam bahasa jurnalistik, ragam bahasa ilmiah, ragam bahasa sastra), (2) ragam bahasa berdasarkan medium pembicaraan (ragam lisan: percakapan, pidato, kuliah; ragam tulis: teknis, catatan, undangundang, surat), dan (3) ragam bahasa berdasarkan hubungan antara pembicara (ragam bahasa resmi, ragam bahasa akrab, ragam bahasa baku, ragam bahasa formal, dan ragam bahasa informal) (Kridalaksana 1992: 3).

Bahasa adalah sistem tanda yang digunakan oleh manusia untuk berkomunikasi dengan orang lain. Masyarakat pemakai bahasa secara sadar atau tidak sadar menggunakan bahasa yang hidup dan dipergunakan dalam masyarakat. Sebaliknya, bahasa juga dapat mengikat anggota masyarakat pemakai bahasa yang bersangkutan menjadi satu masyarakat yang kuat, bersatu, dan maju (Kartomihardjo, 1988: 1). Bahasa tidak dapat dipisahkan dengan masyarakat pemakainya. Bahasa digunakan untuk berkomunikasi untuk mengetahui apa makna ujaran yang disampaikan oleh petutur (Adnyana dkk. 41) Sedangkan, sastra adalah karya tulis yang jika dibandingkan dengan 
tulisan lain, memiliki berbagai ciri keunggulan, seperti: keaslian, keartistikan, keindahan dalam isi dan ungkapannya. Sastra adalah sebuah karya seni yang memiliki ciri-ciri sebagai berikut: (1) sebuah ciptaan, kreasi, bukan imitasi. (2) luapan emosi yang spontan. (3) bersifat otonom. (4) otonomi sastra bersifat koheren (ada keselarasan bentuk dan isi). (5) menghadirkan sintesis terhadap hal-hal yang bertentangan. (6) mengungkapkan sesuatu yang tidak terungkapkan dengan bahasa sehari-hari (Wellek dan Warren, 1993).

Ragam bahasa dan sastra yang terdapat pada karya sastra tradisional Bali dapat dipakai sebagai media pendidikan bagi masyarakat. Salah satunya terdapat dalam teks Geguritan Luh Lutung yang digunakan sebagai objek penelitian. Teks Geguritan Luh Lutung mengandung nilai-nilai filsafat kehidupan yang nantinya dapat dipakai sebagai media pendidikan. Teks Geguritan Luh Lutung dipakai sebagai media pendidikan dengan proses pembacaannya dalam tradisi mabebasan. Tradisi mabebasan merupakan perihal berbahasa tentang pemberian arti dan pemberian makna dalam karya sastra tradisional. Mabebasan melakukan kegiatan membaca sekaligus menembangkan sloka bahasa Kawi disertai terjemahannya dalam bahasa Bali dan kadangkadang diikuti dengan ulasan dengan memakai bahasa Bali atau bahasa Indonesia kalau situasi kontektual menghendakinya (Mastini, 2019: 1). Membaca sebuah geguritan tidaklah seperti membaca sebuah prosa pada umumnya, karena geguritan dibangun oleh pupuh-pupuh yang diikat oleh pada lingsa.

Teks Geguritan Luh Lutung berbentuk puisi yang terdiri dari pupuh-pupuh yang diikat dengan pada lingsa dan isinya menceritakan tentang sosok perempuan yang pantang menyerah belajar hingga mampu mencapai moksa. Pada lingsa sebagai sebuah pola persajakan dalam sastra tradisional Bali atau konvensi yang mengikat kontruksi suatu geguritan melalui pemahaman masyarakat. Secara etimologis pada lingsa dibentuk oleh dua 
kata, yaitu pada (bahasa Sansekerta) 'kaki' dan lingsa 'bunyi'. Pemaknaan yang lebih spesifik dalam konteks (geguritan), pada lingsa mencakup tentang: (1) Jumlah baris (palet) dalam setiap bait (pada), yang disebut guru gatra. (2) Jumlah suku kata (kecap) dalam setiap baris, yang disebut guru wilangan, dan (3) Jatuhnya bunyi vokal suku kata terakhir dalam setiap baris, yang disebut guru lagu/dhongdhing (Saputra, 1992: 8), atau guru suara (Tinggen, 1982: 31).

Berdasarkan latar belakang di atas dapat dirumuskan dua permasalahan, yaitu (1) Bagaimanakah ragam bahasa dalam teks Geguritan Luh Lutung sebagai media pendidikan bagi masyarakat?. (2) Bagaimanakah ragam sastra dalam teks Geguritan Luh Lutung sebagai media pendidikan bagi masyarakat?. Tujuan dari penelitian ini untuk melestarikan khazanah budaya khususnya dalam karya sastra tradisional Bali. Selain itu, untuk mengetahui ragam bahasa dan ragam sastra dalam teks Geguritan Luh
Lutung sebagai media pendidikan bagi masyarakat.

\section{METODE PENELITIAN}

Penelitian ini bersifat kualitatif dengan menggunakan metode deskriptif analitik. Metode deskriptif analitik adalah suatu metode yang berfungsi untuk mendeskripsikan atau memberi gambaran terhadap objek yang diteliti melalui data atau sampel yang telah terkumpul sebagaimana adanya tanpa melakukan analisis dan membuat kesimpulan yang berlaku untuk umum. Dengan kata lain, penelitian deskriptif analitis mengambil masalah atau memusatkan perhatian kepada masalah-masalah sebagaimana adanya saat penelitian dilaksanakan, hasil penelitian yang kemudian diolah dan dianalisis untuk diambil kesimpulan (Sugiono, 2009: 29).

Teori yang digunakan dalam penelitian ini adala teori stilistika. Istilah gaya bahasa dengan stile (sebagai pengindonesiaan dari style) pada hakikatnya merupakan teknik, teknik pemilihan ungkapan kebahasaan, dirasa dapat 
mewakili sesuatu yang akan diungkapkan.

Unsur-unsur stile, yaitu: (1) unsur leksikal, sebagai pilihan kata-kata tertentu yang sengaja dipilih oleh pengarang, (2) unsur gramatikal, merupakan pengaturan pada struktur kalimat, (3) retorika, merupakan cara penggunaan bahasa untuk memperoleh efek estetis, yang didalamnya termasuk: (a) pemajasan (gaya bahasa), dan (b) penyiasatan struktur (kalimat/kebahasaan), (4) pencitraan/image, merupakan rangsangan indera melalui ungkapan-ungkapan bahasa tertentu dalam karya sastra, dan (5) kohesi, merupakan hubungan yang bersifat mengaitkan antara bagian kalimat atau antar kalimat (Nurgiyantoro 2007: 277).

Dengan demikian, teori stilistika miliknya Nurgiyantoro digunakan untuk menganalisis gaya bahasa teks Geguritan Luh Lutung. Selan itu, ditunjang dengan stratifikasi Bahasa Bali atau unda usuk Bahasa Bali guna mengungkapkan ragam bahasa yang digunakan.

\section{PEMBAHASAN}

\subsection{Ragam Bahasa}

Bahasa sebagai suatu hal yang netral dengan mengatakan bahasa adalah lembaga sosial berada di luar manusia, yang memiliki sistem linguistik (kode) sudah ada sebelum orang-orang menyampaikan pesannya dalam bentuk tuturan (Damono, 1984: 40). Dengan demikian melalui pengolahan atau modifikasi unsur-unsur bahasa akan melahirkan kode bahasa sehingga memberikan acuan terhadap gaya bahasa dan ragam bahasa yang akan digunakan dalam menganalisis teks Geguritan Luh Lutung. Geguritan merupakan sebuah puisi naratif, karena dilihat dari segi bentuk adalah puisi yang terdiri dari pupuh-pupuh, sedangkan dari segi isinya merupakan bercerita (naratif) (Parta, 2014: 1). Percakapan antar tokoh didalam cerita teks Geguritan Luh Lutung dianalisis dengan melihat stratifikasi bahasa yang digunakan.

Ragam bahasa merupakan model penggunaan bahasa (sehari-hari) dalam teks, 
dalam hal ini menyangkut tentang penggunaan

Bahasa Bali dalam teks Geguritan Luh Lutung.

Secara umum, Bahasa Bali memiliki dua dialek, yaitu: dialek Bali Aga dan dialek Bali Dataran.

Dengan berbagai pertimbangan kebahasaan, dialek Bali Dataran diadopsi menjadi pembentuk Bahasa Bali Baku. Bahasa Bali Dataran memiliki stratifikasi/tingkatan-tingkatan bahasa yang disebut juga dengan istilah: unda usuk, sor singgih, anggah-ungguhing basa, sebagai akibat dari adanya stratifikasi masyarakat Bali tradisional (wangsa) yang masih berlaku dan bermodifikasi sampai saat ini.

Deskripsi mengenai stratifikasi Bahasa Bali, seperti: Bahasa Bali Alus, Bahasa Bali Madya, dan Bahasa Bali Kasar. Selanjutnya, analisis ragam bahasa dapat dimulai dengan menguraikan deskripsi dialog antartokoh dan mencermati penggunaannya di dalam teks Geguritan Luh Lutung. Pemakaian Bahasa Bali Alus merupakan Bahasa Bali yang mempunyai nilai rasa yang tinggi atau hormat, tersusun atas kata-kata/kalimat yang mengandung pengertian halus, dan digunakan dalam pergaulan untuk menghormati lawan bicara. Ruang lingkup penggunaan Bahasa Bali Alus dalam teks Geguritan Luh Lutung, meliputi:

\section{a. Ranah Keluarga}

Penggunaan Bahasa Bali Alus digunakan untuk menghormati orang yang berstatus lebih tinggi, seperti: cara berbicara anak kepada orang tua, istri terhadap suami, pembantu kepada majikan, dan dalam keluarga yang lebih luas, misalnya: kepada sepupu yang lebih tua, paman, dan lain sebagainya (Santika, 2020). Di dalam teks Geguritan Luh Lutung hal ini digunakan oleh tokoh Made Saliksik saat berbicara kepada ayahnya dan Made Saliksik berbicara kepada kakaknya. Hal ini ditunjukkan pada kutipan berikut ini:

Sapunika pangucape tur bangras/ I Made nyalempoh ngeling/ "Durus bapa kuda/ duaning titiang wus iwang"/ Gurunnyane ngamalihin/ tur mapidartal pitutur mangres resin// (Pupuh Durma I, bait ke-3).

Okannyane sigsigan raris manyumbah/ tahen ring raga pelih/ nunas sinampura/ ngalungsur kaluputan/ : "Diastu pejah titiang ngiring/durus 
wecanaang/ tan waneh mamiragi"// (Pupuh Durma I, bait ke-7).

I Saliksik nunas malih sane mabuat/ "Titiang telas mangiring/ luir panuduh bapa/ diastu ngemasin pejah/ ngranjing ring samudra api/ wantah nyuunang/ masuk jurang kali trebis"// (Pupuh Durma I, bait ke-11).

Raris matur dane Made tur manyumbah/ :"Titiang ngiring ne mangkin/ nunas ke sinupat/ pujane mautamal gurunnya asung nugrahin/ raris mamarga/ I Sliksik saha pamit"// (Pupuh Durma I, bait ke-23).

Sampun puput/ Sang Resi katinggalin sampun/ tan kocap ring marga/ I Made wus mamendakin/ tur asemu guyu/ embok ayu wawu praptall (Pupuh Pucung, bait ke-13).

Terjemahan:

Demikian ucapannya lancang/ I Made bersimpuh menangis/ silahkan ayah marah/ karena saya memang salah/ ayahnya kembali lagi/ dan memberi tahu/ memberi nasihat menakutkan// (Pupuh Durma I, bait ke-3).

Anaknya menangis tersedu-sedu lalu menyembah/ sadar akan diri salah/ memohon maaf/ atas kesalahannya/ meskipun mati saya menuruti/ silahkan katakan/ saya pasti mendengarkan// (Pupuh Durma I, bait ke-7).

I Saliksik memohon yang sarat lagi/ saya akan menuruti semua/ segala perintah ayah/ meskipun mati/ terjun ke samudra api/ saya bersedia/ terjun ke jurang yang terjal// (Pupuh Durma I, bait ke-3).

Lalu I Made berkata dan menyembah/ kini saya menuruti/ mohon agar direstui/ sembah yang utama/ orang tuanya merestui/ lalu berjalan/ I Sliksik mohon diri// (Pupuh Durma I, bait ke23).
Setelah selesai/ semua pendeta meninggalkan/ tiada diceritakan diperjalanan/ I Made telah datang menjemput/ tampak tersenyum/ kanda cantik baru datang// (Pupuh Pucung, bait ke-13).

Kutipan di atas menggambarkan stratifikasi Bahasa Bali Alus yang dilakukan terhadap tokoh Made Saliksik. Tutur kata yang diucapkan sopan dan menghormati lawan bicaranya. Hal inilah yang dapat ditiru mengenai sopan santun dalam bertutur kata terhadap lawan bicara sebagai media pendidikan bagi masyarakat.

\section{b. Ranah Masyarakat}

Penggunaan Bahasa Bali Alus dipakai untuk berbicara dan menghormati orang yang belum dikenal, berwangsa/berkasta lebih tinggi, berpangkat/pejabat dan kepada guru (Santika, 2021). Di dalam teks Geguritan Luh Lutung hal ini digunakan oleh tokoh Made Saliksik dan Luh Lutung ketika berbicara dengan gurunya. Hal ini ditunjukkan pada kutipan berikut ini:

Dane Made tur nyembah aris/ :"Titiang wang Mayural pati luplup paling titiang rekel mawasta titiang Made Saliksik/ nyadia titiang mangkin, manyawita ring Jro Dukuh// (Pupuh Mijil, bait ke-4). 
"Sapunapi caran titiang mangkin/ duaning nunas kawot/ satuhu ring Jro Dukuh saking mangkel kramaning pangajian sane pingit/ mangda ke sane tuil "Jro Dukuh gagisun/l (Pupuh Mijil, bait ke-5).

I Made sumahur aris/ :"Ngarti titiang yan punikal ne mawasta trikaya rekol inggihan trimeda ika/ trigana wantah punikal ngolah dikalane idup/ mahungu manyambut karyal/ (Pupuh Semarandana, bait ke-21).

Made Ungu raris maturl :"Nunas titiang tunggun urip/ kapurwannyane punikal sangkannyane siang latri/ panjang linggahnya punikal ukurannyane amun napi"// (Pupuh Ginanti I, bait ke-7).

"Nyadia titiang ngaturang juita/ ring jeng Hyang Ida Sidi jati/ titiang nunas swecan ratu/ bekel titiang manjadmal tunggun urip yadin pacang tekeng lampus/margane nemu apadang/ mangda suud titiang paling"// (Pupuh Pangkur, bait ke-10).

Made Awas matur sembah/ :"Nunas pidarta sane tui mabukti/ cacakane mawasta letuh/ kalih mawasta utama/ ledang ratu mangeturin titiang dusun/ saking eka pidartayang/ mangda sampun kantun singid// (Pupuh Pangkur, bait ke-17).

Titiang nista katindihan lacur/ ring jagat Mayuranel kadang braya nora sudi/ meme bapa sampun lampus/ titiang newek wantah kantun/ wenten prenah arin titiang/ I Saliksik ne kawuwus/ sampun minggat duk jajaka/ sampun wenten solas temuang// (Pupuh Adri, bait ke-2).

Terjemahan:

I Made menjawab halus dan menyembah/ hamba orang Mayura/ hamba kebingungan datang kemari/ hamba bernama I Made Saliksik/ kini hamba bersedia/ mengabdi kepada tuan Dukuh// (Pupuh Mijil, bait ke-4).
Bagaimanakah caranya hamba kini/ karena memberatkan/ selamanya bagi Tuan Dukuh sejak kini/ tata cara mempelajari hal-hal yang rahasia/ agar yang rahasia itu/ Tuan Dukuh segera menjawab// (Pupuh Mijil, bait ke-5).

I Made berkata halus/ hamba dapat mengerti hal itu/ yang disebut Trikaya itu/ ataupun Trimeda itu/ demikian pula Triguna itu/ yang mengatur tatkala hidup/ yang mengingatkan untuk mengambil pekerjaan// (Pupuh Semarandana, bait ke-21).

Made Ungu lalu bertanya/ hamba menanyakan ujung kehidupan/ asal mulanya itu/ asal siang dan malam/ panjang dan lebarnya/ seberapa ukurannya// (Pupuh Ginanti I, bait ke-7).

Hamba bersedia menyerahkan jiwa/ ke hadapan Tuanku Pendeta/ hamba mohon kesudian Tuanku/ sebagai bekal hamba menjadi manusia/ selama hidup hingga mati/ jalan yang terang/ agar hamba berhenti bingung// (Pupuh Pangkur, bait ke-10).

Made Awas menghaturkan sembah/ memohon ajaran yang terbukti yang dinamakan kotor/ atau pula yang bernama utama/ senanglah tuan menasehati hamba yang bodoh/ jelaskanlah mulai dari satu/ agar tidak sulit// (Pupuh Pangkur, bait ke-17).

Hamba nista tertimpa kemiskinan/ di negeri Mayura/ tetangga masyarakat tiada sudi/ ayah ibu sudah meninggal/ hanya hamba tinggal sendiri/ ada adik hamba/ yang dinamakan I Saliksik/ sudah minggat sejak remaja/ sudah ada sebelas tahun// (Pupuh Adri, bait ke-2).

Kutipan di atas menggambarkan percakapan tokoh Made Saliksik dan Luh Lutung kepada masing-masing gurunya. Bertutur kata yang sopan merupakan cerminan 
dari kepribadian diri. Cara bertutur kata yang sopan sesuai stratifikasi Bahasa Bali ditunjukkan oleh Made Saliksik dan Luh Lutung. Tutur kata yang mereka lakukan sebagai bentuk rasa santun dan menghormati gurunya. Pada masyarakat, ada pepatah yang sering diwacanakan sebagai bentuk menjaga perkataan setiap manusia, yaitu diibaratkan "mulutmu harimaumu". Istilah tersebut dianggap mempunyai konotasi negatif bahwa setiap perkataan yang diucapkan dapat menyakiti orang lain yang mendengarnya. Selain itu, istilah tersebut memiliki makna bahwa setiap kata atau perkataan memiliki kekuatan yang sangat besar manfaatnya bagi diri sendiri maupun bagi orang lain. Dengan demikian, ragam bahasa mengenai stratifikasi Bahasa Bali sangat penting untuk media pendidikan bagi masyarakat.

\subsection{Ragam Sastra}

Ragam sastra yang akan dianalisis dalam penelitian ini berupa gaya bahasa dalam teks Geguritan Luh Lutung. Gaya bahasa adalah cara mengungkapkan pikiran melalui bahasa secara khas, sebagai refleksi dari jiwa dan kepribadian penulis (pemakai bahasa) yang di dalamnya terdapat unsur kejujuran, sopan santun, dan menarik (Tarigan, 1985: 5). Lebih lanjut dikatakannya, bahwa ragam gaya bahasa, meliputi: (1) Gaya Bahasa Perbandingan, antara lain: perumpamaan, metafora, personifikasi, repersonifikasi, alegori, antitesis, pleonasme, perifrasis, antisipasi, koreksio, (2) Gaya Bahasa Pertentangan, antara lain: hiperbola, litotes, ironi, oksimoron, paronomasia, paralipsis, zeugma, innuendo, antifrasis, paradok, klimak, antiklimak, apostrof, anastrof, apofasis, proteron, hipalase, sinisme, sarkasme, (3) Gaya Bahasa Pertautan, antara lain: metonomia, sinekdoke, alusi, eufimisme, eponim, epitet, antonomasia, erotesis, paralelisme, ellipsis, asindeton, polisindeton, dan (4) Gaya Bahasa Perulangan, antara lain: alitrasi, asonansi, kiasmus, epizeukis, taupotes, anafora, epistrofa, simploke, mesodiplosis, anadiplosis.

Di dalam Bahasa Bali, gaya bahasa tersebut dikenal juga dengan istilah basita 
paribasa, yaitu bicara atau kata-kata, ajaran, teguran, celaan, hardikan, ambukan, dan hukuman (Simpen, 1980: 1). Lebih jauh dikatakanya, bahwa basita paribasa, mencakup:

(1) Sesonggan (pepatah), (2) Sesenggakan (ibarat), (3) Wewangsalan (tamil), (4) Sloka (bidal), (5) Beladbadan (metafora), (6) Peparikan (pantun indah), (7) Pepindan (perumpamaan), (8) Sesawangan (perumpamaan), (9) Cecimpedan (teka-teki), (10) Cecangkriman (syair teka-teki), (11) Cecangkitan (olok-olokan), (12) Raos ngempelin (pelawak), (13) Sesimbing (sindiran), (14) Sesemon (sindiran halus), (15) Sipta (alamat), (16) Sesapan (doa).

Di dalam hubungannya dengan struktur karya sastra, keberadaan gaya bahasa mempunyai peranan yang cukup penting. Seorang pengarang yang tampil akan memanfaatkan bahasa untuk menciptakan nada dan suasana yang tepat guna, sehingga dapat memukau pembaca (Santika, 2017). Terlebih pada karya sastra puisi tradisional (geguritan), sangat mementingkan sekali peranan gaya bahasa dalam pencapaian sebuah maksud dengan tidak sama sekali meninggalkan nilai estetis. Gaya bahasa (sastra) yang juga disebut stilistika, merupakan penggunaan bahasa dalam karya sastra yang dipertentangkan (berbeda) dengan penggunaan bahasa diluar karya sastra, seperti: gaya bahasa formal, koran, keilmuan, humor, percakapan, dan lain-lainnya (Atmazaki, 1990: 93). Persoalan gaya bahasa bukanlah pada efisiensi dan efektivitas penggunaannya, melainkan tentang penggunaannya untuk mencapai efek tertentu, yang tidak saja menyangkut tentang keindahan, melainkan tentang kemantapan penggunaannya.

$$
\text { Demikianlah beberapa deskripsi }
$$
mengenai gaya bahasa. Pada dasarnya gaya bahasa mencakup tentang pengertian secara umum, dan penggunaannya dalam karya sastra yang mempunyai peranan yang penting. Penjabaran gaya bahasa secara umum telah dijabarkan secara teliti oleh Tarigan. Dalam hubungannya dengan karya sastra, beberapa ahli 
di atas memiliki kesamaan, bahwa bahasa dalam sastra mencangkup majas/gaya bahasa seperti yang tersebut diatas. Dengan demikian, kajian gaya bahasa dalam teks Geguritan Luh Lutung hanya dilihat pada gaya bahasa (majas) yang ada di dalamnya.

Deskripsi gaya bahasa secara lengkap, teliti, maupun rinci oleh Tarigan akan digunakan sebagai acuan, dengan membandingkan dan mengkombinasikan dengan deskripsi gaya bahasa yang lazim disebut di Bali dengan istilah basita paribasa oleh Simpen. Deskripsi model Tarigan diharapkan mampu mencermati secara mendetail keberadaan gaya bahasa pada teks Geguritan Luh Lutung. Sedangkan deskripsi model Simpen sebagai bagian dari tata Bahasa Bali, mempunyai suatu hubungan erat dengan pengarang sebagai masyarakat penutur Bahasa Bali, dan teks Geguritan Luh Lutung sebagai karya sastra Bali. Dengan demikian analisis gaya bahasa terhadap teks Geguritan Luh Lutung dapat dilakukan. Gaya bahasa pada teks Geguritan Luh Lutung dapat dikelompokkan kedalam gaya bahasa perbandingan, pertentangan, pertautan, dan perulangan. Masing-masing kelompok tersebut mempunyai bagian-bagian yang akan diuraikan selanjutnya di bawah ini:

Gaya bahasa perbandingan, meliputi: sepuluh jenis gaya bahasa, yang pertama adalah perumpamaan. Perumpamaan merupakan padanan kata smile dalam Bahasa Inggris yang berasal dari bahasa Latin yang berarti "seperti”. Dengan demikian, perumpamaan berarti perbandingan dua hal yang pada hakikatnya berlainan, dan sengaja kita anggap sama (Tarigan, 1985: 9). Dalam gaya bahasa (basita paribasa) pada Bahasa Bali, perumpamaan sepadan dengan pepindan, sesawangan, dan sesenggakan (ibarat), pepindan pada dasarnya sama dengan sesawangan. Perbedaannya hanya pada penggunaan kata pembanding, seperti: buka, kadi, luir, dan sebagainya, yang ditempatkan di awal maupun di tengah kalimat pada sesawangan, sedangkan penggunaan kata pembanding di atas tidak dipakai pada pepindan, 
dan adanya nasalisasi yang menyertainya.

Sesenggakan (ibarat) pada dasarnya mirip

dengan sesawangan, namun pada sesawangan

secara konsisten diawali oleh kata pembanding

buka. Contoh perumpamaan dalam teks

Geguritan Luh Lutung dapat dijumpai sebagai

berikut:

- Luir jun kirangan isi (Pupuh Durma I, bait ke-10) 'seperti tempayan kekurangan air' atau 'bagai orang yang tidak memiliki pendirian akan mudah terombang-ambing'.

- Luir pembahing toya (Pupuh Durma I, bait ke-16) 'seperti aliran air' atau 'bagai orang yang berguru, senantiasa harus berbakti dan prilaku berguru agar dipahami'.

- Luir kodok ragan ceninge (Pupuh Durma I, bait ke-17) 'seperti kodok dirimu' atau 'bagai kodok yang mencari telaga bukan telaga yang mencari kodok'.

- Luir pancorang kendi (Pupuh Durma I, bait ke-17) 'seperti pancoran kendi' atau 'berlaksanalah sekuatnya, bila setiap kosong harus dipenuhi'.

- Tan bina manonton ringgit (Pupuh Semarandana, bait ke-2) 'bagaikan menonton wayang' atau 'meributkan hal yang tidak ada'.

- Luir mangadu pucuking rwi (Pupuh Ginanti I, bait ke-9) 'seperti mengadu ujung duri' atau 'melaksanakan pekerjaan yang sia-sia'.

- Kadi ia manising madu (Pupuh Ginanti I, bait ke-10) 'bagaikan ia manisnya madu' atau 'meskipun dapat dikecapi, manisnya tanpa bukti tidak ada wujudnya'.
- Yuyu nyelepang kebo umpami (Pupuh Ginanti I, bait ke-12) 'seperti ketam menelan kerbau' atau 'melakukan pekerjaan yang sia-sia atau tidak masuk akal'.

- Andeang paksi ia mangumbang (Pupuh Ginanti I, bait ke-17) 'seperti burung ia terbang' atau 'bagaikan burung yang terbang tidak tahu jalan pulangnya'.

- Luirne keris manjing urangka (Pupuh Pangkur, bait ke-1) 'seperti keris yang masuk ke dalam sarungnya'.

- Luir bulan tejane lakamadan (Pupuh Sinom II, bait ke-5) 'seperti sinar bulan yang diselimuti'.

- Luir madu drawa wos awor (Pupuh Megatruh, bait ke-10) 'seperti cucuran madu yang menyatu'.

Gaya bahasa perbandingan berikutnya adalah personifikasi. Personifikasi berasal dari bahasa latin persona 'orang', pelaku 'aktor', atau topeng dalam drama. Dengan perkataan lain, penginsanan atau personifikasi adalah jenis majas yang melibatkan sifat-sifat insani kepada barang yang tidak bernyawa dan ide yang bersifat abstrak (Tarigan, 1985: 17). Di dalam teks Geguritan Luh Lutung dapat diperoleh contoh personifikasi sebagai berikut:

- Prabote melah (Pupuh Durma I, bait ke6) 'setiap orang yang lahir sudah membawa senjata yang lengkap'.

- Idep-idepan kaguwanin (Pupuh Mijil, bait ke-10) 'seperti terpikirkan ibarat sebuah goa'. 
- Wisane kadonga bangun (Pupuh Semarandana, bait ke-5) 'racunnya terlanjur bangun'.

- Tur alon ia ngandika (Pupuh Ginanti I, bait ke-5) 'beliau berkata pelan'.

- Made Ungu matur alus (Pupuh Ginanti I, bait ke-13) 'Made Ungu berkata dengan halus'.

- Mangandika ulat guyu amanis (Pupuh Pangkur bait ke-11) 'berkata dengan manisnya'.

- Ne ngwangunan iseng hati (Pupuh Ginanti II, bait ke-8) 'yang membuat hati kangen'.

- Luh Lutung ya nyalang gading (Pupuh Sinom II, bait ke-3) 'Luh Lutung kulitnya kuning mulus'.

- Latinnyane rengat manis (Pupuh Sinom II, bait ke-3) 'alisnya runcing indah'.

- Rambute demdem tur wilis (Pupuh Sinom II, bait ke-3) 'rambut hitam kelam berombak'.

- Cacingake ulem manis (Pupuh Sinom II, bait ke-3) 'pandangannya sayu manis'.

- Wetise mamudak gading (Pupuh Sinom II, bait ke-3) 'betisnya seperti pudak mulus'.

- Susu gemuh nyotong gading (Pupuh Sinom II, bait ke-4) 'payudara montok seperti jambu kuning'.

- Dada widang mangurangka (Pupuh Sinom II, bait ke-4) 'dada lebar bak gagang keris'.

- Wacanane sarwi harum (Pupuh Adri, bait ke-1) 'kata-katanya serba manis'.

Gaya bahasa perbandingan berikutnya adalah Antitesis. Antitesis berarti lawan yang tepat atau 'pertentangan yang benar-benar' (KBBI daring). Antitesis adalah gaya bahasa yang mengadakan komparasi atau perbandingan antara dua antonim yaitu kata-kata yang mengandung ciri-ciri semantik yang bertentangan (Tarigan, 1985: 27). Di dalam teks Geguritan Luh Lutung dapat dijumpai antitesis sebagai berikut:

- Peteng lemah (Pupuh Maskumambang, bait ke-5) 'siang malam'.

- Ngucapang suka duka (Pupuh Pucung, bait ke-14) 'mengucapkan suka dan duka'.

- Wiadin pejah ibu aji (Pupuh Pucung, bait ke 14) 'dan juga kematian ibu dan ayah'.

- Meme bapa titiang lampus (Pupuh Pucung, bait ke-17) 'ibu ayah hamba mati'.

- Jawa Bali wantah patuh (Pupuh Pucung, bait ke-56) 'Jawa Bali sama saja'.

Demikianlah gaya bahasa yang terdapat dalam teks Geguritan Luh Lutung. Bagianbagian lainnya dari gaya bahasa perbandingan selain yang tersebut di atas, tidak dijumpai penggunaannya dalam teks Geguritan Luh Lutung.

Selanjutnya, akan dicermati gaya bahasa pertentangan di dalam teks Geguritan Luh Lutung. Gaya bahasa pertentangan juga memiliki bagian-bagian, yang pertama adalah hiperbola. Hiperbola adalah gaya bahasa yang 
mengandung pernyataan yang berlebih-lebihan dari segi jumlah, ukuran atau sifat, dengan maksud memberikan penekanan pada suatu pernyataan atau situasi, guna memperhebat/meningkatkan kesan dan pengaruhnya (Tarigan, 1985: 55). Di dalam teks Geguritan Luh Lutung keberadaan hiperbola dapat dijumpai sebagai berikut:

- Kimud dane tidong gigis (Pupuh Sinom I, bait ke-9) 'ia sungguh amat sangat malu'.

- Okane sigsigan raris manyumbah (Pupuh Durma I, bait ke-7) 'anaknya menangis tersedu-sedu lalu menyembah'.

- Masuk jurang kali trebis (Pupuh Durma I, bait ke-11) 'terjun ke jurang yang terjal'.

- Katetesan sanjiwani (Pupuh Durma I, bait ke-22) 'diperciki air kehidupan'.

- Tekan ceninge tur lucut (Pupuh Mijil, bait ke-3) 'kedatanganmu basah kuyup'.

- Mangandika ulat guyu amanis (Pupuh Pangkur bait ke-11) 'berkata dengan manisnya'.

- Tur mari anganyi manis (Pupuh Demung, bait ke-6) 'suara lembut tiada hentinya'.

- Ketug linuh ujan angin (Pupuh Demung, bait ke-10) 'gempa bumi hujan badai'.

- Muang gelap nyander ya nitir (Pupuh Demung, bait ke-10) 'disertai petir menyambar'.

Gaya bahasa pertentangan berikutnya adalah Litotes. Litotes adalah gaya bahasa mengandung pernyataan yang dikecil-kecilkan, dikurangi dari kenyataan yang sebenarnya, misalnya untuk merendahkan diri (Tarigan, 1985: 58). Di dalam teks Geguritan Luh Lutung dapat dijumpai penggunaanya sebagai berikut:

- Ring genahnyane kaucap, ring Nabastala kastawi, mula tos kaulan ida, ida ratu murbeng bumi, kastah namane sujati, langkung tambete kawuwus, saking pangkah milu ngawia, pupuh lagu salah gending, ampura ratu, sastranyane akeh tuna. (Pupuh Sinom I, bait ke-2) 'diceritakan tempatnya, bernama Nabastala, memang abdi beliau, yang menguasai alam semesta, namanya sudah terkenal, namanya sudah terkenal, sering disebut bodoh, terlalu berani ikut mengarang, dengan aturan metrum kurang tepat, maafkanlah, atas banyak kesalahannya'.

- Adoh saking kawiswara, titiang punggung manginutin, saksat ngunggahin acala, dekah pacang manututin, sapunika yan upami, inab dura rasan ipun, luir rempah kirang uyah, wantah sang ledang ngecapin, singnya lulut, sang suka ring rasan getas. (Pupuh Sinom I, bait ke-3) 'jauh daripada pengarang besar, saya bodoh mengikuti, seperti menaiki gunung, terengah-engah mengikuti, demikian jika diumpamakan, mungkin kurang kenikmatannya, seperti bumbu kurang garam, hanya yang senang merasakan, yang senang keindahan, yang suka akan rasa garam'.

- Sane manggeh kalinggayang, dening sang muda mangawi, sekat nagarane rundah, peteng lemah maminehin, 
dumadak ratu katampi, mapakardi saking punggung, manyumbungan katuturan, uptian Ida Sang Hyang Hari, maring ipun, Gurun Lutung ia wastannya. (Pupuh Sinom I, bait ke-4) 'yang dipilih sebagai cerita, oleh yang bodoh mengarang, sejak negeri ini kacau siang malam berpikir, semoga bisa diterima, berkarya atas kebodohan, menyuguhkan kisah cerita, penjelmaan Sang Hyang Hari, kepada dia, yang bernama Guru Lutung'.

- Okannyane sigsigan raris manyumbah, tahen ring raga pelih, nunas sinampura, ngalungsur kaluputan, :"Diastu pejah titiang ngiring, durus wecanaang, tan waneh mamiragi". (Pupuh Durma I, bait ke-7) 'anaknya menangis tersedu-sedu lalu menyembah, sadar akan diri salah, memohon maaf, atas kesalahannya, meskipun mati saya menuruti, silakan katakana, saya pasti mendengarkan'.

- Titiang nista katindihan lacur, ring jagat Mayurane, kadang braya nora sudi, meme bapa sampun lampus, titiang newek wantah kantun, wenten prenah arin titiang, I Saliksik ne kawuwus, sampun minggat duk jajaka, sampun wenten solas temuang. (Pupuh Adri, bait ke-2) 'hamba nista tertimpa kemiskinan, di negeri Mayura, tetangga masyarakat tiada sudi, ayah ibu sudah mati, hanya hamba tinggal sendiri, ada adik hamba, yang dinamakan I Saliksik, sudah minggat sejak remaja, sudah ada sebelas tahun'.

Kutipan di atas menjelaskan gaya

bahasa pertentangan dalam teks Geguritan Luh

Lutung. Bagian-bagian lain dari gaya bahasa pertentangan tidak disebutkan, karena tidak ditemukan penggunaannya dalam percakapan antar tokoh pada dalam teks Geguritan Luh Lutung.

Berikutnya akan dicermati gaya bahasa pertautan yang mempunyai bagian-bagian, yang pertama adalah Eufemisme. Eufemisme adalah gaya bahasa ungkapan yang halus sebagai pengganti ungkapan yang dianggap kasar, merugikan, atau tidak menyenangkan (Tarigan, 1985: 28). Penggunaannya dalam teks Geguritan Luh Lutung dapat dijumpai sebagai berikut:

- Pupuh lagu salah gending (Pupuh Sinom I, bait ke-2) 'sebab pupuhnya tidak tepat'.

- Titiang nista katindihan lacur (Pupuh Adri, bait ke-2) 'hamba nista tertimpa kemiskinan'.

Gaya bahasa selanjutnya adalah Antonomasia. Antonomasia adalah gaya bahasa yang merupakan penggunaan gelar resmi atau jabatan sebagai pengganti nama diri (Tarigan, 1985 : 132). Penggunaannya dalam teks Geguritan Luh Lutung dapat dijumpai sebagai berikut :

- Gurun Lutung (Pupuh Sinom I, bait ke4) 'ayah'. 
- Jro Dukuh (Pupuh Mijil, bait ke-3) 'sang guru'.

- Sang Sadaka (Pupuh Ginanti I, bait ke8) 'sang pendeta'.

- Dang Guru, Dang Hyang Guru (Pupuh Pangkur, bait ke-4,6) 'guru besar'.

- Bagawan (Pupuh Pangkur, bait ke-5) 'bagawan/sang guru'.

- $\quad$ Rsi (Pupuh Pangkur, bait ke-9) 'rsi/sang guru'.

- Ida Pranda (Pupuh Pangkur, bait ke-11) 'tuan pendeta/sang guru'.

Kutipan gaya bahasa di atas menunjukkan gelar atau jabatan sebagai pengganti nama pada nama tokoh dalam teks Geguritan Luh Lutung. Adapun tujuan penggunaan gaya bahasa yang terdapat dalam teks Geguritan Luh Lutung adalah untuk memperindah karya sastra dan sebagai daya tarik bagi pembaca. Gaya bahasa yang ditemukan pada teks Geguritan Luh Lutung adalah gaya bahasa perbandingan, seperti: perumpamaan, personifikasi, antitesis. Gaya bahasa pertentangan, seperti: Hiperbola, dan litotes. Gaya bahasa pertautan, seperti: Eufemisme, dan antonomasia.

\section{PENUTUP}

\section{Simpulan}

1. Ragam bahasa dalam teks Geguritan Luh Lutung yang ditemukan berupa stratifikasi Bahasa Bali. Penggunaan Bahasa Bali Alus ditemukan pada ranah keluarga percakapan antartokoh Made Saliksik kepada orang tuanya dan ranah masyarakat dalam percakapan antartokoh Made Saliksik dan Luh Lutung terhadap gurunya.

2. Ragam sastra dalam teks Geguritan Luh Lutung yang digunakan dalam penelitian ini berupa gaya bahasa perbandingan, seperti: perumpamaan, personifikasi, antitesis. Gaya bahasa pertentangan, seperti: Hiperbola, dan litotes. Gaya bahasa pertautan, seperti: Eufemisme, dan antonomasia.

\section{Daftar Pustaka}

Adnyana, I. K. S, Made Suwendi, Dayu Novita Yogan Dewi. (2018). "Dominasi Lakilaki pada Masyarakat Matrilineal Suku Tetun, Kabupaten Malaka, Nusa Tenggara Timur Berdasarpada Penggunaan Bahasa". Prosiding Seminar Nasional Menggali Pengalaman Pembelajaran Bahasa dan 
Sastra Indonesia di Sekolah. Program Studi Pendidikan Bahasa dan Sastra Indonesia. Universitas Pendidikan Ganesha. Singaraja 20-21September 2018. Halaman 40-50.

Atmazaki. 1990. Ilmu Sastra: Teori dan Terapan. Padang: Angkasa Raya Padang

Damono, Sapardi Djoko. 1984. Sosiologi Sastra: Sebuah Pengantar Ringkas. Jakarta: Pusat Pembinaan dan Pengembangan Bahasa Departemen Pendidikan dan Kebudayaan.

Kartomihardjo, Soeseno. 1988. Bahasa Cermin Kehidupan Masyarakat. Jakarta: Departemen Pendidikan dan Kebudayaan, Direktorat Jenderal Pendidikan Tinggi, Proyek Pengembangan Lembaga Pendidikan Tenaga Kependidikan.

Kridalaksana, Harimurti. 1992. Kelas Kata dalam Bahasa Indonesia. Jakarta: Gramedia.

Kridalaksana, Harimurti. 2001. Kamus Linguistik. Jakarta: PT Gramedia Pustaka Utama.

Mastini, Gusti Nyoman. 2019. Tradisi Mabebasan Sebagai Upaya Pelestarian Bahasa Bali. Denpasar: Kalangwan: Jurnal Pendidikan Agama, Bahasa, Dan Sastra Agama. Vol. 9 No. 1 Maret 2019. https://ejournal.ihdn.ac.id/index.php/Kal angwan/article/view/1077/917.

Nurgiyantoro, Burhan. 2007. Teori Pengkajian Fiksi. Yogyakarta: Gadjah Mada.

Parta, Ida Bagus Made Wisnu. 2014. Analisis Stilistika Dalam Pupuh-Pupuh Karya Sastra Tradisional Bali. Denpasar: Jurnal Widya Acharya. Oktober 2014. http://ejournal.undwi.ac.id/index.php/wi dyaaccarya/article/download/35/23

Saputra, Karsono H. 1992. Pengantar Sekar Macepat. Jakarta: Fakultas Sastra Universitas Indonesia.

Simpen AB. I Wayan. 1980. Basita Paribasa. Denpasar: Upada Sastra
Sugiono. 2009. Metodologi Penelitian Kualitatif dan $R \& D$. Bandung: Alfabeta.

Tarigan, Henry Guntur. 1985. Pengajaran Gaya Bahasa. Bandung: Angkasa.

Tinggen,I Nengah. 1982. Aneka Rupa Basa Bali. Singaraja.

Wellek, Rene dan Warren, Austin. 1993. Teori Kesusastraan (terjemahan melalui Budiyanto). Jakarta: Gramedia.

https://kbbi.kemdikbud.go.id/entri/antitesis Diakses 30 Agustus 2021. 